\title{
Comparison of formation of visco-elastic masses and their properties between zeins and kafirins
}

Janet Taylor*, Joseph O. Anyango ${ }^{1}$, Peter J. Muhiwa ${ }^{2}$, Segun I. Oguntoyinbo and John R.N. Taylor

Institute for Food, Nutrition and Well-being and Department of Food Science, University of Pretoria, Private Bag X 20, Hatfield 0028, South Africa

*Corresponding Author: Janet Taylor

Phone: +27 124205402

Fax: +27 124202839

E-mail: janet.taylor@up.ac.za

1.Present address: Department of Dairy, Food Science and Technology, Faculty of Agriculture, Egerton University, P.O. Box 536-20115, Egerton, Njoro, Kenya.

2. Present address: Ministry of Agriculture, Irrigation and Water Development, Chikwawa District Agriculture Office, Post Office Box 39, Chikwawa, Malawi

Additional Authors

Joseph O. Anyango : ajochieng@egerton.ac.ke

Peter J. Muhiwa : muhiwapeter@yahoo.com

Segun I. Oguntoyinbo :graceyetty2020@gmail.com

John Taylor: john.taylor@up.ac.za 


\section{Highlights}

- Zein and kafirin visco-elastic masses can be formed by coacervation

- Visco-elastic mass formation not dependent of prolamin sub-class composition

- Zein visco-elastic masses are largely viscous, kafirin masses more elastic

- $\quad \gamma$-subclass needed for zein and kafirin visco-elastic mass softness retention

- $\quad \gamma$-subclass needed for kafrin visco-elastic mass elastic recovery retention

\section{Abstract}

Zeins of differing sub-class composition much more readily formed visco-elastic masses in water or acetic acid solutions than equivalent kafirin preparations. Visco-elastic masses could be formed from both zein and kafirin preparations by coacervation from glacial acetic acid. Dissolving the prolamins in glacial acetic acid apparently enabled protonation and complete solvation. Stress-relaxation analysis of coacervated zein and kafirin visco-elastic masses showed they were initially soft. With storage, they became much firmer. Zein masses exhibited predominantly viscous flow properties, whereas kafirin masses were more elastic. The $\gamma$-sub-class is apparently necessary for the retention of visco-elastic mass softness with kafirin and zein, and for elastic recovery of kafirin. Generally, regardless of water or acetic acid treatment, all the zein preparations had similar FTIR spectra, with greater $\alpha$-helical conformation, than the kafirin preparations which were also similar to each other. Kafirin visco-elastic masses have a much higher elastic character then zein masses.

Keywords: Kafirin, zein, visco-elastic mass, acetic acid, rheology 


\section{Introduction}

There are two compelling reasons for research into the science and technology of making wheatfree leavened dough products. The first is to enable production of gluten-free products for the increasing number of celiac sufferers, where the only treatment is life-long abstinence from gluten containing products. The second reason is to reduce the need for expensive wheat imports in countries where the climatic conditions are unsuitable for wheat production except under irrigation. Various methodologies have been used for the production of gluten-free leavened products. They include the addition of hydrocolloids and other functional ingredients to starch or gluten-free flours, and non-gluten containing protein mixtures or modification of "gluten-free" prolamin proteins such as zein (from maize) or kafirin (from sorghum). These modifications attempt to improve the functionality of these prolamins in ways that allow them to replace the visco-elastic properties of gluten in leavened products. This latter approach is potentially very beneficial to countries where sorghum and maize are major crops.

It is well known that visco-elastic masses, sometimes termed doughs or resins, can be made from commercial hydrated zein in aqueous systems above the glass transition temperature $\left(T_{g}\right)$ of hydrated zein (Schober, Moreau, Bean, \& Boyle, 2010). When mixed with starch or rice flour above zein's $T_{g}$, doughs with similar visco-elastic and gas-holding properties to wheat flour doughs can be made (Lawton, 1992; Sly, Taylor \& Taylor, 2014), enabling the production of wheat-free breads of reasonable quality (Schober et al., 2010). Other workers have tried to form visco-elastic masses from kafirin under similar conditions without success (Oom, Pettersson, Taylor, \& Stading, 2008). These workers attributed the failure to form visco-elastic masses from kafirin to the use of an extraction procedure which isolated kafirins without correct functional properties for dough formation. It is known that the conditions used for extraction and purification of prolamins influence the composition and functionality of those prolamins (Bean, loerger, Park, \& Singh, 2006). Schober, Bean, Tilley, Smith, \& loerger, (2011) used a range of different extraction procedures in an attempt 
to extract proteins that were functional for visco-elastic aggregate formation. These workers only got functionality in terms of visco-elastic aggregate formation with zein extracted with $70 \%$ ethanol. The presence of $\mathrm{NaOH}$ or sodium metabisulphite as part of the extractant resulted in non-functional zein. Functional zeins were characterised by high levels of $\alpha$-zeins, and low levels of $\beta+\gamma$-zeins. Conversely, non-functional zeins were characterised by high levels of $\beta+\gamma$-zeins. $\beta+\gamma$-zeins are more hydrophilic than $\alpha$-zeins and contain more cysteine than $\alpha$-zeins. A ratio of $\beta+\gamma$-zeins $/ \alpha$-zeins of $10 \%$ or less was found to give the maximum functionality of zein in terms of visco-elastic aggregate formation. When a high proportion of $\beta+\gamma$-zeins were present, the possibility of more disulphide cross-linking occurring was higher. Disulphide bonding does not appear to be responsible for zein visco-elastic aggregate formation (Schober et al., 2011; Smith, Bean, Selling, Sessa, \& Aramouni,2014), and may even have a negative effect by preventing aggregation of $\alpha$-zein helices (Schober et al., 2011). It is plausible that disulphide cross-linking actually interferes with visco-elastic aggregate formation. Non-covalent interactions, specifically hydrophobic interactions, have been shown to have a role in the formation of visco- elastic materials from zein, (Smith et al., 2014).

Another factor which is thought to influence visco-elastic mass formation in zein is the secondary structure of the protein. Secondary structural changes from mainly $\alpha$-helical to $\beta$-sheet were found when zein was mixed with water above its $\mathrm{T}_{\mathrm{g}}$ and a visco-elastic mass was formed (Mejia, Mauer, \& Hamaker, 2007). When the shear stress caused by mixing was stopped, the amount of $\beta$-sheet structures rapidly decreased in favour of unordered structures with a concomitant decrease in zein visco-elasticity. A decrease in $\beta$-sheet structure was also found when the temperature was reduced below the $T_{g}$ of the protein. These changes were not observed in wheat gluten and led to the theory that the formation of a $\beta$-sheet rich secondary structure was necessary for visco-elastic mass formation in zein (Erickson, Campanella, \& Hamaker, 2012). 
Previous work has shown that a commercial zein visco-elastic mass (referred to as dough), prepared with dilute organic acids, above the $\mathrm{T}_{\mathrm{g}}$ of the protein, had improved functionality in terms of increased extensibility and reduced stress when compared to similar visco-elastic masses made with water (Sly et al., 2014). It found no evidence of hydrolysis or polymerisation caused by acid but FTIR revealed small conformational changes possibly due to deamidation. A study on zein containing all the zein sub-classes $(\alpha-, \beta-, \gamma-, \delta-)$ showed that visco-elastic masses (referred to as dough) could only be formed in water above zein's $T_{g}$, after it had been dissolved in glacial acetic acid and cast into a film (King, Taylor, \& Taylor, 2016). This visco-elastic mass was stronger and less extensible than commercial zein visco-elastic mass made without film formation, probably due to disulphide bond cross-linking. A similar process of dissolving kafirin in glacial acetic acid, and then precipitating the protein on rapid water addition by simple coacervation, yielded a cohesive mass with viscoelastic properties (Elhassan, Oguntoyinbo, Taylor, \& Taylor, 2018). When this process was applied to sorghum lines with either the presence or reduced expression of the cysteine-rich $\beta$ - and $\gamma$-kafirin sub-classes, the visco-elastic masses had different visual appearance, but their stress-relaxation behaviour was similar. Sorghum lines lacking or with reduced $\beta-/ \gamma$-kafirin sub-classes formed viscoelastic masses that when stretched manually exhibited broad ribbon-like fibrils. In contrast, kafirin visco-elastic masses from normal sorghums showed only fine fibrils and what was assumed to be unhydrated kafirin aggregates. The stress-relaxation analysis showed very soft visco-elastic masses, with some elastic properties. Both properties were maintained when the visco-elastic mass was stored at $8^{\circ} \mathrm{C}$, over an extended period. Thus, based on current knowledge, four factors seem to effect visco-elastic mass formation: protein composition in terms of prolamin sub-classes, secondary structure, glass transition temperature and hydrophobicity.

The objectives of this work were specifically to determine which of the above factors has most influence on prolamin visco-elastic mass formation. Additionally, the study directly compared the effect of these factors on zein and kafirin visco-elastic mass formation, which has not up to present 
been investigated. The long-term aim of the work is to determine whether these non-gluten cereal prolamins could potentially substitute for wheat gluten in non-wheat and gluten-free breadmaking. This study took an alternative approach to that of Schober et al., 2011) by starting with nonfunctional kafirin and zeins preparations and taking components away until prolamin functionality was obtained in terms of fibril and visco-elastic mass formation.

\section{Materials and Methods}

\subsection{Extraction of prolamin preparations}

Kafirin was extracted from tan-plant, non-tannin white sorghum cultivar, PANNAR PEX 202/206, which had been decorticated, as described (Emmambux and Taylor, 2003). Gamma-kafirin was extracted from total kafirin using $0.05 \mathrm{M}$ sodium lactate containing $2 \%(\mathrm{v} / \mathrm{v})$ 2-mercaptoethanol (Evans, Schüssler, \& Taylor, 1987, Taylor, Bean, loerger, \& Taylor, 2007) at a protein to solvent ratio of 1:5 (Anyango, Taylor, \& Taylor, 2013). The solid residue after extraction of the $\boldsymbol{y}$-kafirin was designated kafirin minus $\gamma$-kafirin.

Zein was extracted from milled, whole grain white maize using the method for total kafirin extraction. Commercial zein (Sigma Z3625) was obtained from Sigma-Aldrich, Johannesburg, South Africa.

The protein content of the prolamin preparations was determined $(N \times 6.25)$ by a Dumas combustion method, AACC standard method 46-30 (American Association of Cereal Chemists, 2000).

\subsection{Preparation of high $\alpha$-prolamin preparations}

Kafirin, kafirin minus $\gamma$-kafirin, zein and commercial zein were all defatted with hexane at ambient temperature and air dried before being further extracted to obtain high $\alpha$-prolamin preparations. High $\alpha$-prolamin preparations were made essentially according to Schober et al. (2011). The defatted 
laboratory prepared prolamin preparations $(10 \mathrm{~g})$ were extracted with $50 \mathrm{~g} 70 \%(\mathrm{w} / \mathrm{w})$ aqueous ethanol $50^{\circ} \mathrm{C}$, shaking every $15 \mathrm{~min}$. After $1 \mathrm{~h}$, the preparations were centrifuged at $9050 \mathrm{~g}$ for 10 $\min$, the supernatant decanted and the residue re-extracted with a further $50 \mathrm{~g} 70 \%(\mathrm{w} / \mathrm{w})$ aqueous ethanol. Supernatants were combined, placed in open stainless steel trays and the ethanol evaporated off at ambient temperature $\left(25^{\circ} \mathrm{C}\right)$. On ethanol evaporation, excess cold, distilled water $\left(10^{\circ} \mathrm{C}\right)$ was added to precipitate the protein, which was separated by filtration and air dried overnight at $25^{\circ} \mathrm{C}$. These preparations were designated high $\alpha$-prolamin. The weights of recovered high $\alpha$-prolamin preparations were recorded and their protein content determined. The amount $\alpha$ prolamin in the high $\alpha$-prolamin preparations was calculated by dividing the amount of protein recovered after further extraction by the starting weight of protein and expressing it as a percentage-.

After characterisation by 2D-electrophoresis (Figure 1), the prolamin preparations were designated: kafirin or zein (containing $\alpha-, \beta-, \gamma-, \delta-)$, kafirin minus $\gamma(\operatorname{containing} \alpha-, \beta-$, and $\delta-)$, commercial zein (mainly $\alpha-$ ), high $\alpha$ - kafirin, high $\alpha$ - zein (mainly $\alpha-$ ).

\subsection{Visco-elastic mass preparation}

Three different methods of prolamin visco-elastic mass preparation were compared: firstly, by mixing the prolamin powder with water or $5.4 \%$ acetic acid at $50^{\circ} \mathrm{C}$ as described by Sly et al. (2014) ( shown below), secondly using the method of Sly et al. (2014) but using 33\% acetic acid. Prolamin powder ( $0.5 \mathrm{~g}$ as is basis) was pre-warmed to $50^{\circ} \mathrm{C}$. Distilled water, $5.4 \%(\mathrm{v} / \mathrm{v})$ or $33 \%(\mathrm{v} / \mathrm{v})$ acetic acid (1.875 g) were pre-warmed separately. The liquid was added to the prolamin powder and vortexed at high speed for $5 \mathrm{~s}$. Excess water or acid was decanted off and the visco-elastic mass was hand-kneaded for $30 \mathrm{~s}$. Finally the coacervation method of Elhassan et al. (2018) was used, as described below. 


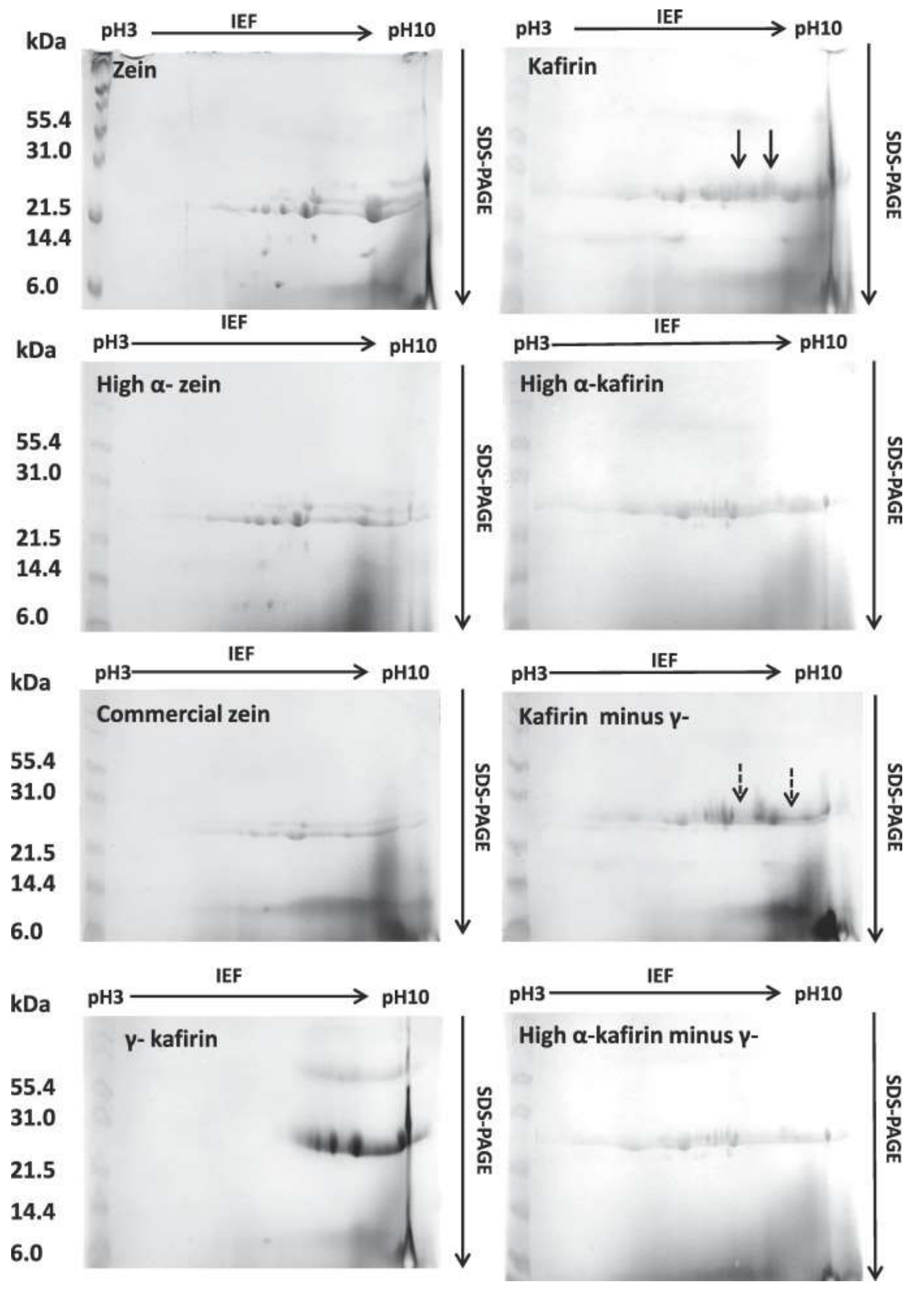

Figure 1. 2D-Electrophoresis of kafirin and zein preparations. Solid arrows mark presumed $\gamma$-kafirin spots. Note the missing spots (marked with dotted arrows) in Kafirin minus $\gamma$-kafirin compared to kafirin. 
Visco-elastic masses were made by modifying the coacervation method for making protein microparticles of Taylor, Taylor, Belton, \& Minnaar, (2009). Protein preparations (0.5 g) were weighed into centrifuge tubes and glacial acetic acid $(2.5 \mathrm{~g})$ added. The mixture was heated to $50^{\circ} \mathrm{C}$ and mixed using a vortex mixer until the protein was completely dissolved. Distilled water $(5 \mathrm{~g}$ at $\left.15^{\circ} \mathrm{C}\right)$ was then rapidly $(5 \pm 1 \mathrm{sec})$ added to the protein solution and the precipitated fibrils were manipulated into a visco-elastic mass using a spatula. The final temperature of the diluted acetic acid was approximately $25^{\circ} \mathrm{C}$, substantially below the $\mathrm{T}_{\mathrm{g}}$ of water hydrated kafirin of around $40^{\circ} \mathrm{C}$ (Schober et al., 2011). The final acetic acid concentration was 33\%. Excess liquid was decanted off and the visco-elastic mass placed in a ziplock bag and stored at $10^{\circ} \mathrm{C}$ overnight. Controls were prepared by weighing the protein preparation $(0.1 \mathrm{~g})$ into a centrifuge tube which was preheated to $50{ }^{\circ} \mathrm{C}$. Acetic acid $(33 \% \mathrm{w} / \mathrm{v})$ and distilled water $(1.5 \mathrm{~g})$ were preheated separately to $50^{\circ} \mathrm{C}$ before being added to the protein preparation and the mixture vortexed at high speed for $30 \mathrm{~s}$. The resulting hydrated solid or visco-elastic mass was stored in a ziplock bag at $10^{\circ} \mathrm{C}$ overnight.

\subsection{D Electrophoresis}

Protein preparations were solubilized $(5 \mu \mathrm{g} / \mu \mathrm{l})$ in a solution containing $7 \mathrm{M}$ urea, $2 \mathrm{M}$ theorem, $4 \%$ w/v 3-[(3-Cholamidopropyl)dimethylammonio]-1-propanesulphonate (CHAPS), 2\% v/v immobilized $\mathrm{pH}$ gradient (IPG) buffer $\mathrm{pH}$ 3-10 and $40 \mathrm{mM}$ dithiothreitol (DTT). Electrophoresis was carried out according to Adebowale, Emmambux, Beukes, \& Taylor, (2011). Gels were stained with Coomassie Brilliant Blue R-250 and images acquired using a Versa Doc Documentation system (Bio-Rad, Hercules, Canada).

\subsection{Stereomicroscopy of visco-elastic masses}

The morphology of the visco-elastic masses or hydrated solids was studied at $400 \times$ magnification, using a Nikon Stereo Light microscope (Nikon SMZ 800 stereo microscope, Tokyo, Japan) fitted with 
a Nikon DXM 1200 digital camera. Each visco-elastic mass $(5 \times 3 \times 1.5 \mathrm{~mm})$ was stretched by hand, placed onto a glass slide and then released before it was imaged and photographed.

\subsection{Confocal Laser Scanning Microscopy (CLSM)}

Preparations were made by evaporating ethanol from $100 \mu$ l of high $\alpha$-prolamin extracts directly on a microscope slide. Two drops of distilled water was then added to precipitate the protein. Slides were viewed using a Zeiss 510 META system (Jena, Germany) CLSM with a Plan-Neofluar $10 \times 0.3$ objective under natural fluorescence at an excitation wavelength of $488 \mathrm{~nm}$.

\subsection{Stress-relaxation of visco-elastic masses}

Kafirin and zein visco-elastic masses were prepared as described above. All zein visco-elastic masses were extremely soft when first prepared and so were stored in a zip-lock bag for $4 \mathrm{~h}$ at $10^{\circ} \mathrm{C}$ before analysis. Kafirin visco-elastic masses, which were more firm, were analysed immediately. The cohesive mass pieces ( $0.5 \mathrm{~g}$ ) were pressed (within $30 \mathrm{sec}$ ) into a longitudinal split, cylindrical flexible plastic mould ( $4 \mathrm{~mm}$ long $\times 5 \mathrm{~mm}$ internal diameter) to obtain a visco-elastic mass piece of uniform shape and size with excess protein material being removed from the ends of the mould using a spatula. The visco-elastic mass piece was de-moulded and then transferred onto the base plate of a Shimadzu Scientific Instruments EZ-Test texture analyser (Kyoto, Japan), fitted with a $10 \mathrm{~mm}$ cylindrical probe for analysis. A single compression test was carried out with a test speed of 0.5 $\mathrm{mm} / \mathrm{s}$, distance $1 \mathrm{~mm}$ and a relaxation time of $100 \mathrm{~s}$. The stress-relaxation properties of vital wheat gluten visco-elastic mass hydrated with distilled water ( $52 \%$ moisture dry powder basis) were determined for comparison. Tests were repeated at 5, 10 and $15 \mathrm{~min}$ on the same visco-elastic mass preparations.

All the visco-elastic mass preparations were then stored at $10^{\circ} \mathrm{C}$ in sealed ziplock type plastic bags. The same visco-elastic mass pieces were analysed again after 2 days and 16 days storage. $F$ Max (the 
maximum force at compression), Ft (the force at the time from $\mathrm{F}$ Max at which fresh gluten had relaxed to $38.6 \%$ of its maximum force ( 11.6 seconds ) and SR (\% stress recovery at 11.6 seconds from F Max) were measured according to Singh, Rockall, Martin, Chung, \& Lookhart, (2006).

\subsection{Fourier transform infrared spectroscopy (FTIR)}

FTIR spectroscopy, as described (Taylor et al. 2009) was used to determine protein secondary structures. Dry protein preparations were further dried over silica gel for $72 \mathrm{~h}$, whereas visco-elastic masses or hydrated solids (as prepared for stereomicroscopy) were used directly. Preparations were scanned using a Vertex 70v FT-IR spectrophotometer (Bruker Optik, Ettlingen, Germany), using 64 scans, $8 \mathrm{~cm}^{-1}$ band width and an interval of $1 \mathrm{~cm}^{-1}$ in the Attenuated Total Reflectance (ATR) mode in wavenumber range $600-4000 \mathrm{~cm}^{-1}$. The FTIR spectra were normalized and Fourier-deconvoluted using Lorentzian filter with a resolution enhancement factor of 2 and $8 \mathrm{~cm}^{-1}$ band width. The ratios of peak intensity at 1650 and $1620 \mathrm{~nm}$ were calculated to indicate different contents of $\alpha$-helices and intermolecular $\beta$-sheets, respectively.

\subsection{Differential scanning calorimetry (DSC)}

Thermal analysis was performed by DSC using a Mettler Toledo HP DSC827 $7^{\mathrm{e}}$ (Schwerzenbach, Switzerland) as described by Anyango et al. (2013). Freeze-dried samples were further dried in a desiccator containing silica gel for 14 days. DSC scans were performed from $25-280^{\circ} \mathrm{C}$ and heating rate of $10^{\circ} \mathrm{C} / \mathrm{min}$ under nitrogen (40 bar pressure). Glass transition $\left(\mathrm{T}_{\mathrm{g}}\right)$ peaks were taken at the peak of step change in heat flow during heating and determined using STAR ${ }^{\mathrm{e}}$ software Version 9.20 (Thermal Analysis UserCom; Wang, Rakotonirainy, \& Padua, 2003). 


\subsection{Statistical analysis}

All experiments were repeated at least once, except for FTIR and DSC which were repeated three times. Data were analyzed by one-way analysis of variance (ANOVA). Significant differences among the means were determined by Fisher's least significant difference (LSD) test $(p<0.05)$.

\section{Results and Discussion}

\subsection{Prolamin preparation composition}

Two-D electrophoresis was used to establish differences in composition between the various zein and kafirin preparations (Figure 1). Commercial zein was essentially $\alpha$-zein, as demonstrated by the presence of two rows of polypeptide spots of apparent $M_{r}$, approx. 22 and $27 \mathrm{kDa}$ (Figure 1). Although somewhat higher in apparent $M_{r}$, the two rows are consistent with $\alpha$-zein 19 and $\alpha$-zein 22 , respectively (Lawton and Wilson, 2003). Spots of $M_{r}$, approx. $10 \mathrm{kDa}$, were also present. These spots were probably equivalent to $\delta$-zein of apparent $M_{r} 13 \mathrm{kDa}$ as described by Cremer, Bean, Tilley, loerger, Ohm, Kaufman, et al. (2014). Zein contained several higher molecular weight spots of apparent $M_{r}$, approx. 29 kDa (Figure 1), equivalent to $y$-zein (Belton, Delgadillo, Halford, \& Shewry, 2006), in addition to the same polypeptide spots present in the commercial zein preparation. Lower molecular weight spots of apparent $M_{r}$ approx. 18 and $15 \mathrm{kD}$ (Figure 1), consistent with $\mathrm{\gamma}$-zein (16 kDa) and $\beta$-zein (15-18 kDa) (Lawton and Wilson, 2003), were also present. Thus, the zein preparation comprised the major zein sub-classes, $\alpha-, \beta-, \gamma$ - and $\delta$-zein.

Kafirin had a similar pattern of spots to zein (Figure 1) but without the presence of spots at $15 \mathrm{kD}$ and $10 \mathrm{kDa}$. It is likely that the kafirin was more cross-linked than the zein. It is known that in its native state kafirin polymerises by disulphide bonding to a much greater extent than native zein (Emmambux and Taylor, 2009). Two D-electrophoresis is carried out under reducing conditions. However, reduction resistant polymers of isolated kafirin, which are too large to enter a SDS-PAGE gel have been documented (Duodu, Nunes, Delgadillo, Parker, Mills, Belton, \& Taylor, 2002; Da Silva 
and Taylor, 2004; Byaruhanga, Erasmus, \& Taylor, 2005). Reduction resistant, high molecular weight polymers may have been present which were too large to enter the gel, resulting in fewer observed spots in the kafirin gel. Kafirin minus $\psi$ - had the same spot pattern as kafirin, except, as would be expected, for the absence of spots with $M_{r}$ approx. 27 kD (Figure 1), equivalent to $\gamma$-kafirin. The protein preparation identified as $\psi$-kafirin (Figure 1) showed spots over a range of basic $\mathrm{pl}$ of $\mathrm{M}_{\mathrm{r}}$ $27 \mathrm{kD}$, consistent with $\mathrm{p}$-kafirin.

Protein spots in the $18 \mathrm{kDa}$ region were observed in zein, kafirin, kafirin minus $\mathrm{Y}$ - (Figure 1 ) but were absent in commercial zein (Figure 1). A $16 \mathrm{kDa}$ band of $\gamma$-zein and $\gamma$-kafirin has been identified (Belton et al., 2006). However, if these approximately $18 \mathrm{kDa}$ spots were $\gamma$-kafirin then it would be expected to see them in the isolated $\gamma$-kafirin and them not to be present in the preparation of kafirin minus $\gamma$-. The only low molecular weight spot present in the $\gamma$-kafirin was approximately 10 kDa as referred to above. These spots were thus designated $\beta$-prolamins (El Nour, Peruffo, \& Curioni, 1998; Cremer et al., 2014).

Two-D electrophoresis of high $\alpha$-zein and high $\alpha$-kafirin preparations are illustrated in Figure 1 . As would be expected these preparations had less spots or less intense low molecular weight spots, with more intense spots equivalent to $\alpha$-zein or $\alpha$-kafirin than the zein and kafirin preparations.

\subsection{Visco-elastic mass formation}

The effects of the zein and kafirin preparation and of the various water and acetic acid treatments on visco-elastic mass formation are summarised in Table 1S.

Of the prolamin preparation studied, only commercial zein was able to form a visco-elastic mass, when treated with distilled water or $5.4 \%$ acetic acid at $50^{\circ} \mathrm{C}$ (Figure 2). It is known that zein and kafirin prepared by essentially same method as used in this study, did not form a visco-elastic mass 
in water above the protein $\mathrm{T}_{\mathrm{g}}$ (Schober et al. 2011). Thus, the resulting changes to these proteins caused by the acetic acid were insufficient to allow visco-elastic mass formation with the zein, kafirin and kafirin minus $\gamma$. Polymerisation by disulphide cross-linking may have prevented cohesive mass formation under these conditions for all prolamin preparations, except commercial zein. As stated, Schober et al. (2011) suggested that disulphide cross-linking may have a negative effect on cohesive mass formation, by preventing aggregation of $\alpha$-zein helices. Commercial zein was mainly $\alpha$-zein, as shown by 2D-electrophoresis, (Figure 1), and so extensive disulphide bond formation would not be possible.

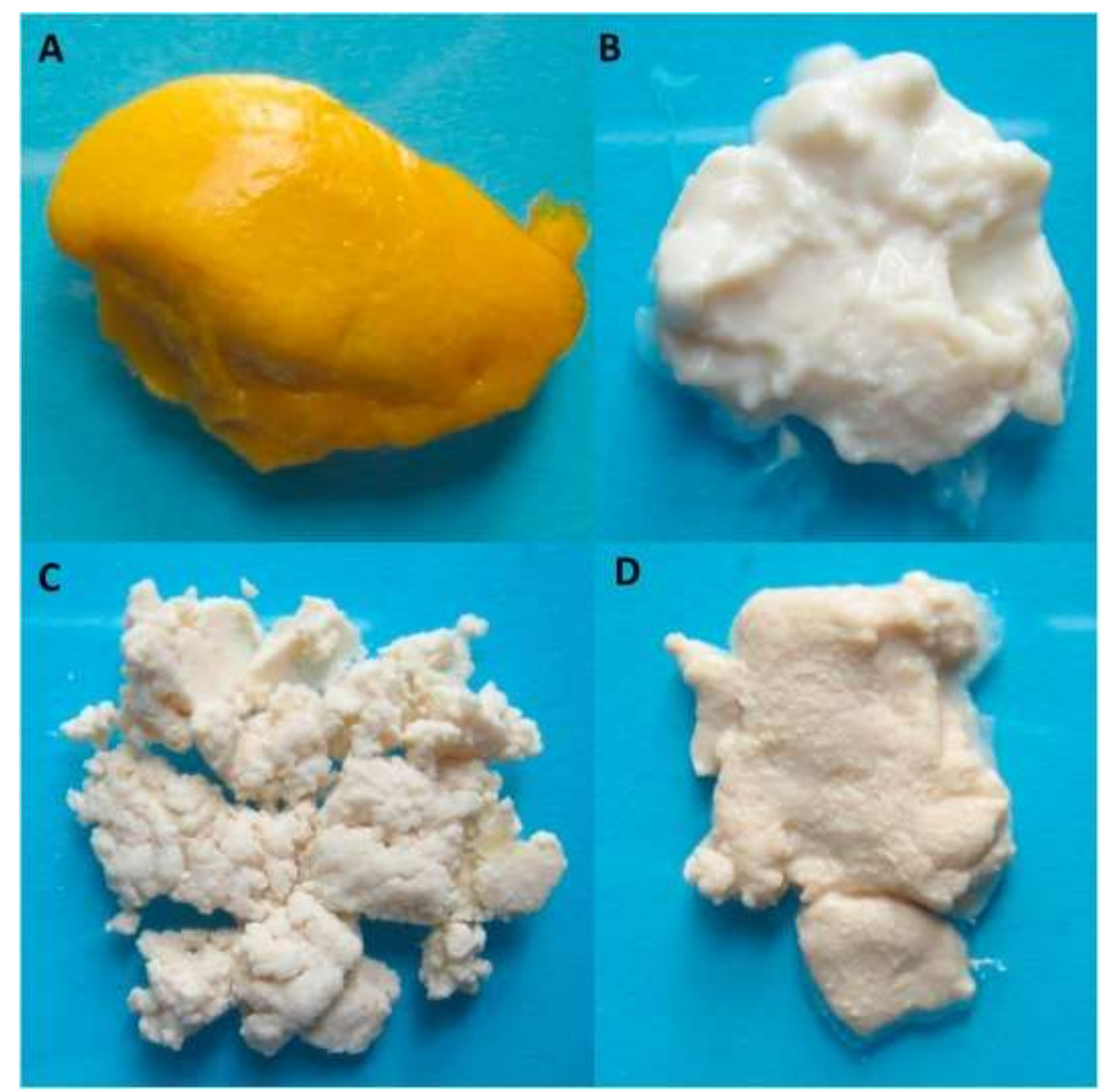

Figure 2. Effects of mixing acetic acid (5.4\%) with kafirin or zein preparations at $50^{\circ} \mathrm{C}$.

A-Commercial zein, B-Zein, C-Kafirin minus $\gamma$-, D-Kafirin A-viscoelastic mass, B-D hydrated aggregates

However, during the isolation of the high $\alpha$-prolamin preparations, it was observed all $\alpha$-prolamins from the various zein and kafirin preparations formed taffy-like visco-elastic masses on precipitation of the proteins on addition of excess water, following removal of some of the ethanol by 
evaporation. These $\alpha$-prolamin visco-elastic masses could be stretched to a greater or lesser degree. The functionality with regard to visco-elastic mass forming properties in terms of cohesiveness and extensibility as judged visually and by manual manipulation in descending order was: $\alpha$-prolamin from commercial zein, from zein, from kafirin minus $\gamma$-. High $\alpha$-kafirin had the worst visco-elastic mass forming properties under these wet conditions. When the water was separated from the protein, the high $\alpha$-zein preparations remained soft and continued to expel a large amount of water. The high $\alpha$-kafirin preparations were stiffer and only expelled a small amount of water. CLSM of these $\alpha$-prolamin preparations under wet conditions, clearly illustrate fibril formation in all preparations (Figure 3A-D). For zein, the formation of protein into strands (fibrils/fibres) has been suggested to be a critical step in dough formation (Schober et al., 2010). Mainly parallel fibrils were observed in the zein and kafirin preparations (Figure 3B, D), with the kafirin preparation in particular exhibiting lateral associations between the fibrils. When relatively more $\alpha$-prolamin was present, in the commercial zein and kafirin minus $\gamma$ preparations, networks of more closely associated fibrils were present (Figure $3 \mathrm{~A}, \mathrm{C}$ ).

However, the formation of these fibrils was transient for all but the commercial zein preparation. As stated above, on drying and milling to a powder, none of the high $\alpha$-prolamin preparations could form fibrils or a visco-elastic mass when mixed with $5.4 \%$ acetic acid at $50^{\circ} \mathrm{C}$. This ability was only retained by commercial zein. The transient nature of fibril and subsequent visco-elastic mass formation may be due to the recurrence of cross-linking when the preparations were dried, resulting in loss of functionality. Evidence of small amounts of $\gamma$-prolamins could be seen by 2D electrophoresis in the high $\alpha$-kafirin and high $\alpha$-zein preparations (Figure 1). Presence of faint $\beta$-zein spots were observed in the high $\alpha$-zein (Figure 1) but were not visible in the either of the kafirin preparations (Figure 1). Possibly some $\gamma$ - and $\beta$-prolamins were present but had formed large reduction-resistant polymers, which could not enter the gels, as described above. 


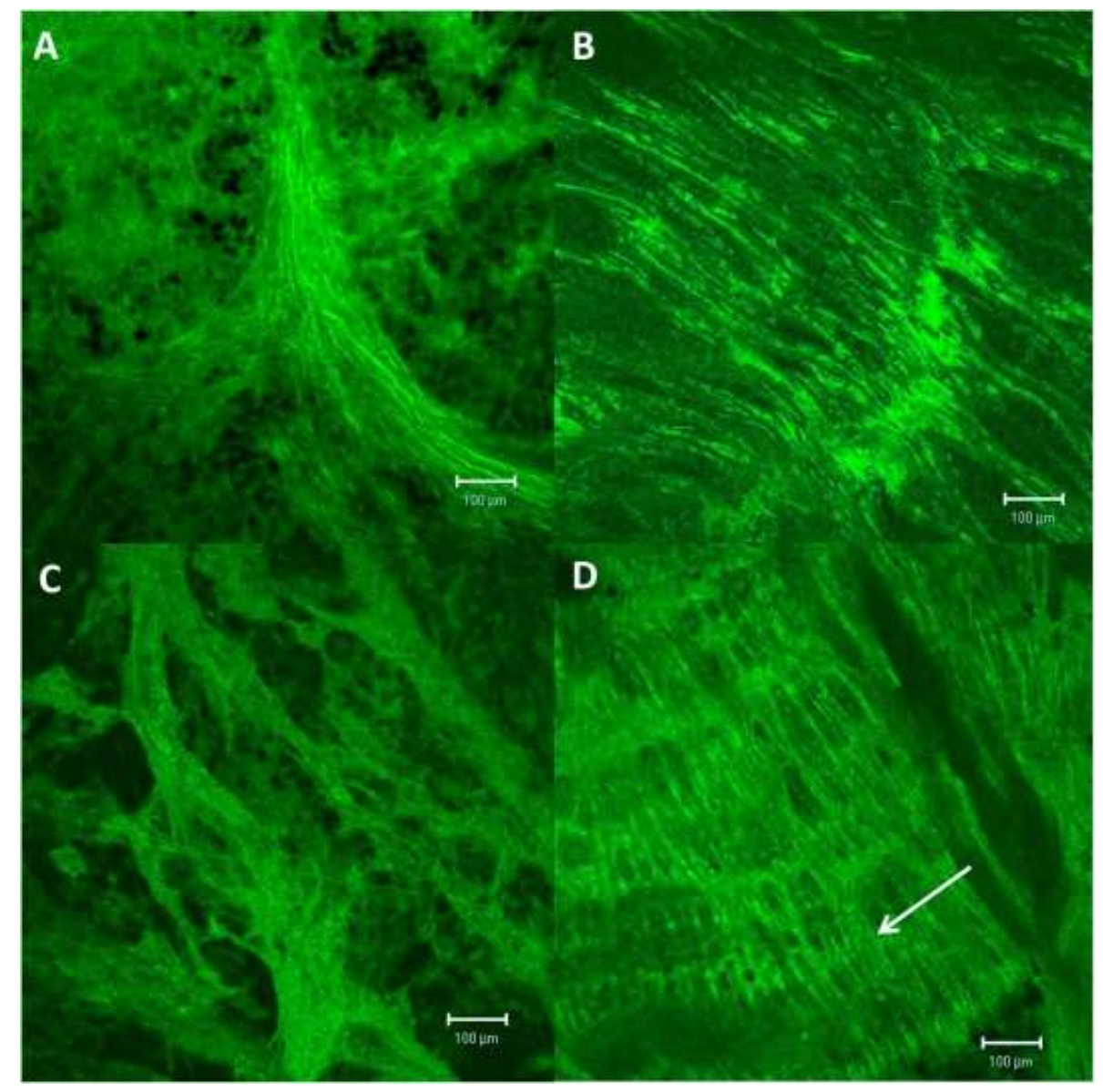

Figure 3. CLSM illustrating fibril formation of different prolamin preparations on precipitation from aqueous ethanol extracts with water during high $\alpha$-prolamin preparation A-Commercial zein, B-Zein, C-Kafirin minus $\gamma$-, D-Kafirin. Arrow shows laterally associated fibrils

Since a reducing agent was not included when extracting the $\alpha$-prolamin preparations, only prolamin monomers or dimers would be extracted (Da Silva, Taylor, \& Taylor, 2011). The relative amounts of $\alpha$-prolamins extracted from the original prolamin preparations as determined gravimetrically, were as follows: commercial zein $100 \%$, zein $81.6 \%$, kafirin $71.4 \%$ and kafirin minus $\gamma-60.9 \%$. These figures give an indication of how polymerised the original prolamin preparations were. The commercial zein was largely un-polymerised. By difference, the degree of polymerisation of the zein, kafirin and kafirin minus $\alpha$ was approximately $20 \%, 30 \%$ and $40 \%$, respectively. The degree of polymerisation is linked to prolamin composition, with the higher amounts of the cysteine containing sub-classes $\beta$ and $\gamma$ - having the greater potential for the formation of disulphide bonds (El Nour et al., 1998). Highly polymerised proteins are more difficult to solubilise and so less functionality would be 
expected in terms of visco-elastic mass formation. Bearing this in mind the zein preparations would have more potential to form visco-elastic masses than the kafirin preparations.

This was borne out when the more hydrophobic condition of $33 \%$ acetic acid was used for viscoelastic mass formation. This resulted in some functionality in terms of fibril and visco-elastic mass formation in all the dried zein preparations (Figure 4). When the commercial zein preparation was mixed with the $33 \%$ acetic acid, the protein precipitated out without forming a visco-elastic mass. When no mixing was applied a very soft, taffy-like visco-elastic mass formed with many fibrils, which disappeared on cooling (Figure 4L). Concerning zein, a cohesive visco-elastic mass was also formed on addition of $33 \%$ acetic acid, which could be stretched and showed numerous fibrils (Figure $4 \mathrm{M}$ ). The high $\alpha$-zein formed an extensible visco-elastic mass, which could be stretched and formed numerous fibrils (Figure $4 \mathrm{~N}$ ). The functionality of the zein and high $\alpha$-zein may have been due to protonation. According to Li, Xia, Zhang, Wang, \& Huang, (2012), protonation of zein with acetic acid causes partial unfolding or swelling of $\alpha$-zein, resulting in more solvent accessible area and hydration of the zein surface.

However, the more polymerised and more hydrophobic (Duodu, Taylor, Belton, \& Hamaker, 2003) dried kafirin preparations still exhibited very little functionality with treatment with $33 \%$ acetic acid. The high $\alpha$-kafirin and high-kafirin minus $\gamma$ even if they did not quite make cohesive visco-elastic masses, some fine fibrils were observable (Figure $4 \mathrm{I}, \mathrm{K}$ ). No fibrils were seen in the kafirin minus $\gamma$ preparation under the same conditions (Figure 4H), whereas kafirin showed slight functionality, again with the presence of few very fine fibrils (Figure 4J). With the kafirin preparations, the $33 \%$ acetic acid may not have been enough to unfold the kafirin molecules sufficiently to allow hydration and thus visco-elastic mass formation. 

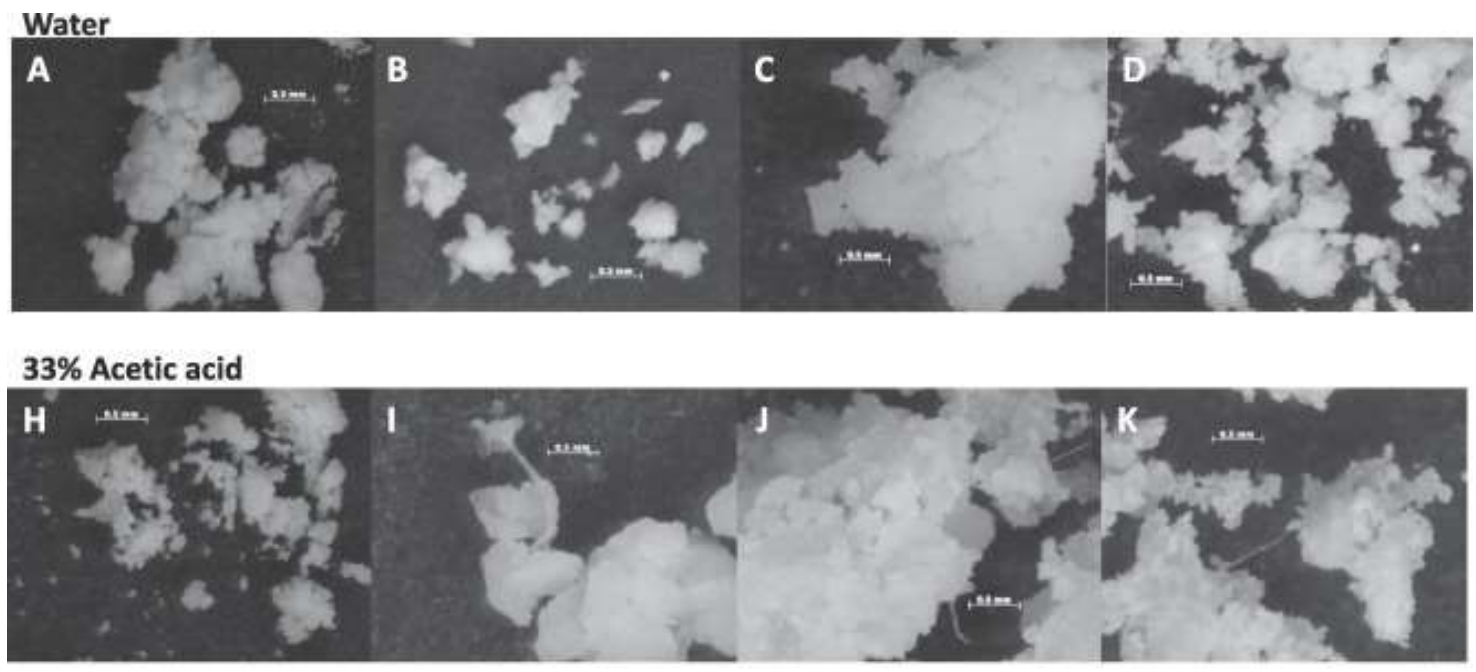

\section{Coacervated}

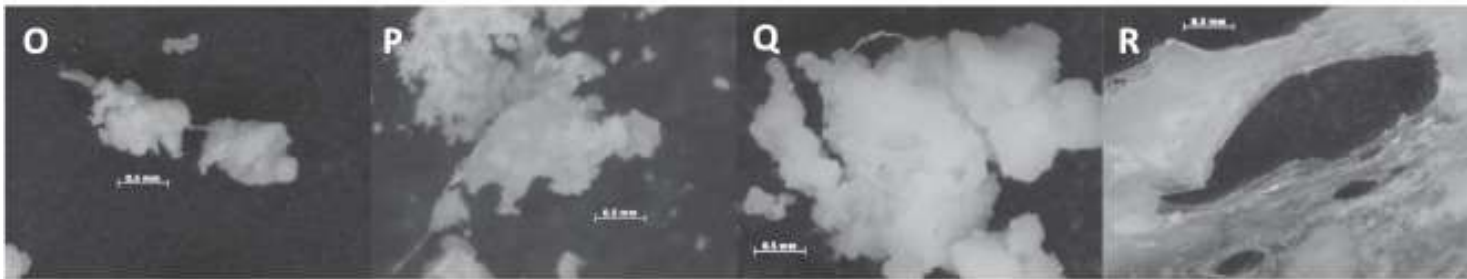

Kafirin minus $-\gamma \quad$ High $\alpha$-kafirin minus $-\gamma$

Kafirin

High $\alpha$-kafirin

Water

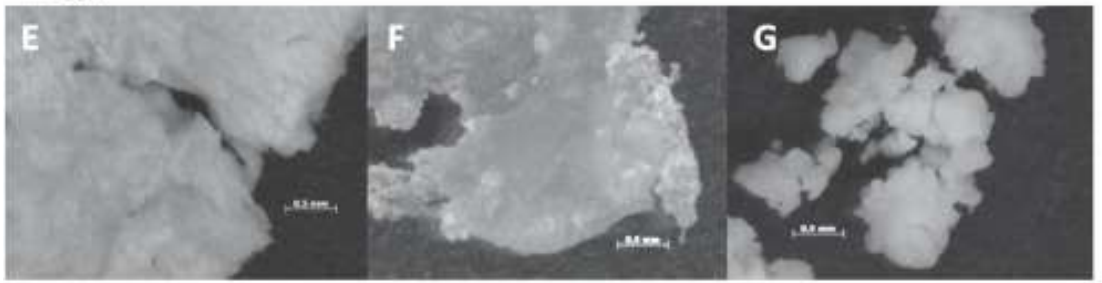

$33 \%$ Acetic acid

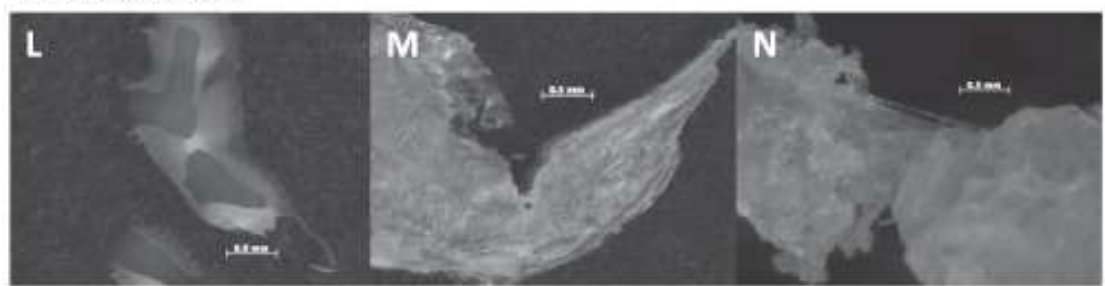

\section{Coacervated}

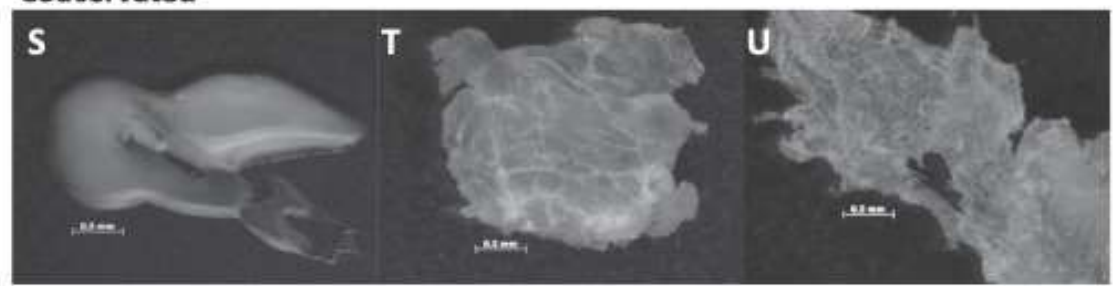

Commercial zein

Zein

High $\alpha$-zein

Figure 4. Stereo microscopy of hydrated aggregates or visco-elastic masses formed from different kafirin and zein preparations treated with either water or $33 \%$ acetic at $50^{\circ} \mathrm{C}$ or coacervated from glacial acetic acid 
Coacervation of the dried prolamin preparations, resulted in fibril formation with all the prolamins, (Figure 4O-R, T, U), except commercial zein which formed a taffy-like mass (Figure 4S). The coacervation process involved solvation of the kafirin and zein preparations in glacial acetic acid prior to water addition and protein precipitation. Zein is fully dissolved in acetic acid, protonated and in the form of monomers (Li et al. 2012). Glacial acetic acid is also a good solvent for kafirin (Taylor, Taylor, Dutton, \& De Kock 2005) and so it would be expected that the kafirin preparations were also protonated and present at least in part as monomers, which were partially unfolded. It is likely that these changes enabled fibril and visco-elastic mass formation on water addition of all the kafirin and zein preparations. Coacervated high $\alpha$-zein and zein both formed extensible cohesive masses when stretched by hand (Figure $4 \mathrm{~T}, \mathrm{U}$ ). The high $\alpha$-zein preparation showed slight elasticity but the zein visco-elastic mass did not. Broad fibrils could be observed when the high $\alpha$-kafirin visco-elastic mass was hand stretched (Figure 4R) and was somewhat more extensible than the equivalent high $\alpha$-zein preparation (Figure $4 \mathrm{U}$ ). All the kafirin visco-elastic masses(Figure 4O-R) showed some elastic properties since they rapidly returned to their original shape on pressing by hand and releasing. This property was retained on cooling and even after several weeks storage at $10^{\circ} \mathrm{C}$ in plastic ziplock bags. Sly et al. (2014) attributed this apparent elasticity to the presence of acetic acid acting as a plasticiser.

\subsection{Visco-elastic mass rheology}

Quantitative measurements of stress -relaxation of coacervated zein and kafirin visco-elastic masses showed that they were very soft and remained so even after repeated compression on day 0 (Table 1), regardless of their composition. In fact, it was not possible to perform stress-relaxation measurements on the zein visco-elastic masses immediately after preparation as they were too soft. The visco-elastic masses were then stored for 4 hours at $10^{\circ} \mathrm{C}$, after which time the visco-elastic masses had become firm enough to measure, although they were still very soft. The firming of the zein visco-elastic preparations may have been due to slight water loss during handling. In contrast, 
gluten visco-elastic masses became firmer with repeated compression on day 0 . With regard to the percentage stress recovery of the visco-elastic masses at day 0 (i.e. not stored), the all kafirin viscoelastic masses exhibited more elasticity than gluten (Table 1 ), whereas the zeins showed predominantly viscous flow properties. In both cases this was regardless of their sub-class composition.

Table 1: Stress-relaxation behaviour of gluten, kafirin and zein visco-elastic masses after repeated compression on day 0 and after storage at $4^{\circ} \mathrm{C}$ for 2 and 16 days

\begin{tabular}{|c|c|c|c|c|c|c|c|c|c|}
\hline \multirow[t]{2}{*}{ Protein Type } & \multicolumn{3}{|c|}{ F Max (N) } & \multicolumn{3}{|c|}{ Ft (N) } & \multicolumn{3}{|c|}{$\%$ SR } \\
\hline & $\begin{array}{c}\text { Day } \\
0\end{array}$ & Day 2 & Day 16 & Day 0 & Day 2 & Day 16 & Day 0 & Day 2 & Day 16 \\
\hline Gluten & $\begin{array}{c}3.538 \\
\pm \\
0.373\end{array}$ & $\begin{array}{c}3.747 \\
\pm \\
0.105\end{array}$ & $\begin{array}{c}6.874 \\
\pm 0.108\end{array}$ & $\begin{array}{c}1.695 \\
\pm 0.200\end{array}$ & $\begin{array}{c}2.110 \\
\pm \\
0.022\end{array}$ & $\begin{array}{c}2.976 \\
\pm 0.125\end{array}$ & $\begin{array}{c}47.9 \mathrm{Ca} \\
\pm 3.0\end{array}$ & $\begin{array}{c}42.2 \mathrm{Ca} \pm \\
4.7\end{array}$ & $\begin{array}{c}43.3 \mathrm{Da} \\
\pm 2.5\end{array}$ \\
\hline Kafirin & $\begin{array}{c}0.073 \\
\pm \\
0.008\end{array}$ & $\begin{array}{c}0.290 \\
\pm \\
0.013\end{array}$ & $\begin{array}{c}0.585 \\
\pm 0.011\end{array}$ & $\begin{array}{c}0.057 \\
\pm 0.010\end{array}$ & $\begin{array}{c}0.248 \\
\pm \\
0.013\end{array}$ & $\begin{array}{c}0.450 \\
\pm 0.023\end{array}$ & $\begin{array}{c}\text { 78.3Ea } \\
\pm 5.2\end{array}$ & $\begin{array}{c}85.7 \mathrm{Fb} \\
\pm 0.4\end{array}$ & $\begin{array}{c}76.9 \mathrm{Fa} \\
\pm 3.3\end{array}$ \\
\hline High $\alpha$-kafirin & $\begin{array}{c}0.091 \\
\pm \\
0.002\end{array}$ & $\begin{array}{c}0.204 \\
\pm \\
0.006\end{array}$ & $\begin{array}{c}2.191 \\
\pm 0.014\end{array}$ & $\begin{array}{c}0.076 \\
\pm 0.002\end{array}$ & $\begin{array}{c}0.185 \\
\pm \\
0.003\end{array}$ & $\begin{array}{c}1.295 \\
\pm 0.021\end{array}$ & $\begin{array}{c}83.4 \mathrm{Fb} \\
\pm 0.4\end{array}$ & $\begin{array}{c}90.7 \mathrm{Fb} \\
\pm 3.9\end{array}$ & $\begin{array}{c}59.1 \mathrm{Ea} \\
\pm 0.6\end{array}$ \\
\hline $\begin{array}{l}\text { Kafirin } \\
\text { minus- } \gamma\end{array}$ & $\begin{array}{c}0.223 \\
\pm \\
0.007\end{array}$ & $\begin{array}{c}1.048 \\
\pm \\
0.001\end{array}$ & $\begin{array}{r}14.856 \\
\pm 0.026\end{array}$ & $\begin{array}{c}0.146 \\
\pm 0.011\end{array}$ & $\begin{array}{c}0.621 \\
\pm \\
0.034\end{array}$ & $\begin{array}{c}4.796 \\
\pm 0.067\end{array}$ & $\begin{array}{c}65.4 \mathrm{Db} \\
\pm 3.0\end{array}$ & $\begin{array}{c}\text { 59.3Eb } \\
\pm 3.3\end{array}$ & $\begin{array}{c}32.3 \mathrm{Ca} \\
\pm 0.5\end{array}$ \\
\hline $\begin{array}{l}\text { High } \alpha \text {-kafirin } \\
\text { minus }-\gamma\end{array}$ & $\begin{array}{c}0.510 \\
\pm \\
0.017\end{array}$ & $\begin{array}{c}4.061 \\
\pm \\
0.008\end{array}$ & $\begin{array}{r}33.970 \\
\pm 2.588\end{array}$ & $\begin{array}{c}0.340 \\
\pm 0.018\end{array}$ & $\begin{array}{c}2.135 \\
\pm \\
0.107 \\
\end{array}$ & $\begin{array}{l}10.967 \\
\pm 2.349\end{array}$ & $\begin{array}{c}66.5 \mathrm{Dc} \\
\pm 1.3\end{array}$ & $\begin{array}{c}52.6 \mathrm{Db} \\
\pm 2.5\end{array}$ & $\begin{array}{c}32.1 \mathrm{Ca} \\
\pm 4.5\end{array}$ \\
\hline Zein & $\begin{array}{c}0.054 \\
\pm \\
0.004\end{array}$ & $\begin{array}{c}0.063 \\
\pm 0.005\end{array}$ & $\begin{array}{c}1.530 \\
\pm 0.072\end{array}$ & $\begin{array}{c}0.009 \\
\pm 0.001\end{array}$ & $\begin{array}{c}0.012 \\
\pm \\
0.002\end{array}$ & $\begin{array}{c}0.404 \\
\pm 0.030\end{array}$ & $\begin{array}{c}16.8 \mathrm{Ba} \\
\pm 1.5\end{array}$ & $\begin{array}{c}18.6 \mathrm{Ba} \\
\pm 4.9\end{array}$ & $\begin{array}{c}26.4 \mathrm{Bb} \\
\pm 0.7\end{array}$ \\
\hline High $\alpha$-zein & $\begin{array}{c}0.080 \\
\pm \\
0.015\end{array}$ & $\begin{array}{c}0.111 \\
\pm \\
0.001\end{array}$ & $\begin{array}{c}7.523 \\
\pm 0.241\end{array}$ & $\begin{array}{c}0.003 \\
\pm 0.001\end{array}$ & $\begin{array}{c}0.003 \\
\pm \\
0.001\end{array}$ & $\begin{array}{c}2.349 \\
\pm 0.111\end{array}$ & $\begin{array}{l}3.1 \mathrm{Aa} \\
\pm 0.3\end{array}$ & $\begin{array}{l}2.3 \mathrm{Aa} \\
\pm 0.7\end{array}$ & $\begin{array}{c}31.2 \mathrm{Cb} \\
\pm 0.5\end{array}$ \\
\hline $\begin{array}{l}\text { Commercial } \\
\text { zein }\end{array}$ & $\begin{array}{c}0.070 \\
\pm \\
0.011 \\
\end{array}$ & $\begin{array}{c}0.200 \\
\pm \\
0.008\end{array}$ & $\begin{array}{r}25.195 \\
\pm 0.474\end{array}$ & $\begin{array}{c}0.003 \\
\pm 0.001\end{array}$ & $\begin{array}{c}0.007 \\
\pm \\
0.001 \\
\end{array}$ & $\begin{array}{c}5.498 \\
\pm 0.856\end{array}$ & $\begin{array}{c}3.5 \mathrm{Aa} \\
\pm 0.4\end{array}$ & $\begin{array}{l}3.5 \mathrm{Aa} \\
\pm 0.6\end{array}$ & $\begin{array}{c}21.8 \mathrm{Ab} \\
\pm 3.0\end{array}$ \\
\hline
\end{tabular}

$\mathrm{F}$ Max.=Maximum force

$\mathrm{Ft}=$ Force at which fresh gluten visco-elastic mass had relaxed to $36.8 \%$ of its maximum force (11.6 s after $\mathrm{F}$ Max)

$\mathrm{SR}=\%$ stress recovery at 11.6 seconds after $\mathrm{F}$ Max

${ }^{a}$ Mean values with different upper case letter in a column differ significantly from each other $(p<0.05)$

${ }^{b}$ Mean values within a protein type with different lower case letter in a row differ significantly from each other $(p<0.05)$

After storage up to 16 days the influence of prolamin composition on the visco-elastic mass firmness was more clearly indicated. The visco-elastic masses could be ranked in terms of firmness after 
repeated compression from the softest to the firmest: kafirin $(0.6 \mathrm{~N})$, zein $(1.5 \mathrm{~N})$, high $\alpha$-kafirin $(2.2$ $\mathrm{N})$, high $\alpha$-zein $(7.5 \mathrm{~N})$, kafirin minus $\gamma(14.9 \mathrm{~N})$, commercial zein $(25.2 \mathrm{~N})$ and high $\alpha$-kafirin minus $\gamma$ $(34.0 \mathrm{~N})$. After 16 days storage, the kafirin visco-elastic mass retained its elasticity $(76.9 \%$ stress recovery). The high $\alpha$-kafirin visco-elastic mass also retained elasticity ( $59.1 \%$ stress recovery), but to a lesser degree than the kafirin visco-elastic mass. This may have been because it contained less $\gamma$ kafirin than the kafirin. The kafirin preparations minus $\gamma$ lost their elasticity on storage and became more viscous, (32.3\% kafirin minus $\gamma, 32.1 \%$ high kafirin minus $\gamma$ stress recovery). From these results it appears that the presence of the $\gamma$-subclass in kafirin is required for the maintenance of viscoelastic mass elasticity on storage. This is in slight contrast to the finding of Elhassan et al. (2018), who found that the presence or absence of the cysteine-rich sub-classes, either $\gamma$ - or $\beta$ - did not greatly affect elastic behaviour, although it did affect the visco-elastic mass physical appearance. This difference may have been as result of $\gamma$-kafirin being actively removed from the kafirin, whereas in Elhassan et al.'s work $\gamma$-kafirin synthesis had been suppressed and compensatory synthesis of other kafirins took place (Da Silva et al., 2011). In the case of the zeins, all the visco-elastic masses showed similar viscous flow character on storage, (only $21.8-31.2 \%$ stress recovery), regardless of the presence or absence of the $\psi$ - sub-class.

\subsection{Secondary structure and stability of zein and kafirin preparations and their visco-elastic masses}

The FTIR spectra of all the dry prolamin preparations showed that the zein preparations were essentially similar to each other, with a wide single peak in the Amide I region with the highest point at $1645 \mathrm{~cm}^{-1}$ and small shoulders close to the 1620 and $1680 \mathrm{~cm}^{-1}$ (Figure 5A). All the kafirin preparations with exception of $\psi$-kafirin were also similar to each other but different from the zein preparations in terms of their FTIR spectra. The kafirin preparations exhibited two well defined peaks in the Amide I region at approximately $1650 \mathrm{~cm}^{-1}$ and $1622 \mathrm{~cm}^{-1}$, whereas the $\gamma^{-k}$-kafirin consisted of a single flat topped, broad peak between $1600-1670 \mathrm{~cm}^{-1}$ (Figure 5A). According to Duodu, Tang, Grant, Wellner, Belton \& Taylor (2001), the peak around $1650 \mathrm{~nm}$ can be assigned to 
$\alpha$-helical conformations and $1620 \mathrm{~nm}$ to anti-parallel $\beta$-sheet conformations, whereas the shoulder at $1680 \mathrm{~nm}$ can be assigned to $\beta$-turns (Kong \& Yu, 2007).
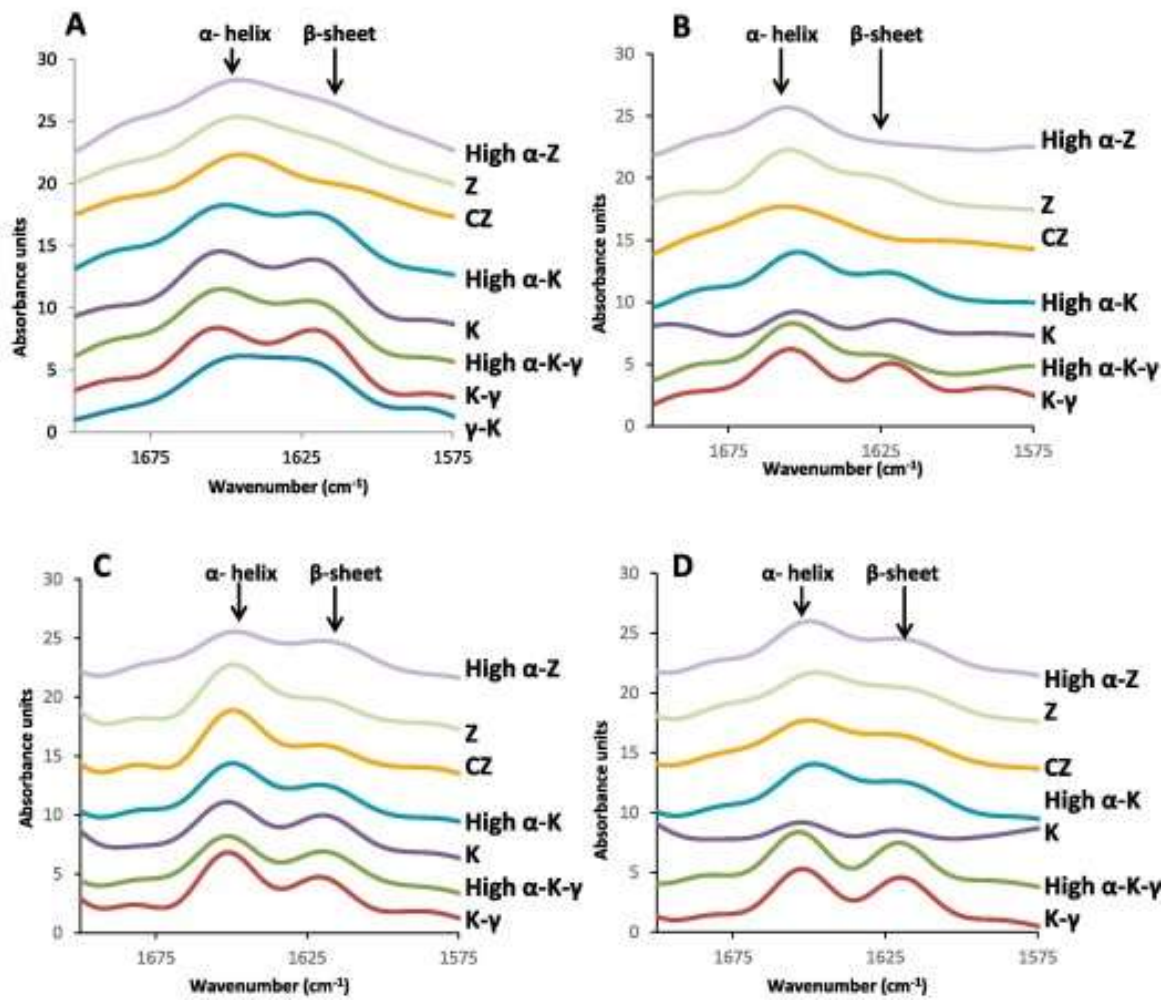

Figure 5. FTIR of different kafirin and zein preparations A- Protein powder, B-Protein powder plus water, CProtein powder plus 33\% acetic acid, D-Protein powder dissolved in glacial acetic acid then coacervated with water, final acid concentration 33\% High $\alpha$-Z -high alpha zein, Z- zein, CZ- commercial zein, High $\alpha-\mathrm{K}-$-high alpha kafirin, K- kafirin, High $\alpha-\mathrm{K}-\gamma$ - high kafirin minus gamma , K- $\gamma$ - kafirin minus gamma, $\gamma$ - -gamma kafirin

The commercial zein had the highest ratio $\alpha$-helix (62\%) to $\beta$-sheet (38\%) conformation in the Amide I region and was the only preparation that showed functionality, when it had been dried and then mixed with dilute $(5.4 \%)$ acetic acid at $50^{\circ} \mathrm{C}$ (Figure 2). All other zein and kafirin preparations had similar but slightly lower ratios, ranging from $56-58 \% \alpha$-helix for the zeins and $53-54 \% \alpha$-helix for the kafirins. These values are similar to the published value of $56.7 \%$ for zein containing all classes (King et al., 2016) and slightly higher than the value for kafirin of approximately 49\% (Xiao, Li, Li, Gonzalez, Xia, Q.,\& Huang2014). However, these values give no insight into changes of secondary structure that may be occurring on visco-elastic mass formation. Work by Mejia et al. (2007) indicates that zein functional visco-elastic masses when mixed above their $\mathrm{T}_{\mathrm{g}}$, lose their native predominately $\alpha$ helical conformation and undergo a structural change to a mainly $\beta$-sheet conformation. These 
workers found this transformation was transient and that when the stress caused by mixing was removed the proportion of $\beta$-sheet decreased.

The finding that the FTIR spectra of the zein preparations were similar to each other, and that of the kafirins were also similar to each other (with the exception of $y$-kafirin), but different from the zeins, was also observed in the water and the coacervated treatments (Figure 5B, D). This appeared to be independent of the prolamin preparation composition in terms of prolamin sub-classes and may have been responsible, at least in part, for the differences in visco-elastic mass forming properties of zein and kafirin. Addition of $33 \%$ acetic acid to the dry prolamin preparations resulted in the biggest difference in the FTIR spectra. All the prolamin preparations exhibited higher and more distinct $\alpha$ helical peaks (Figure 5C). This is in agreement with the findings of Xiao et al. (2014), who found that the $\alpha$-helical content of kafirin increased in solution and was dependant on solvent polarity. As the solvent polarity decreased the amount of $\alpha$-helical structure increased. If the polarity of the different solvents used in this study is considered, water has the highest, 9.0 and glacial acetic acid 6.2 (Lai et al., 2012) and by calculation 33\% acetic acid is 8.1, assuming a linear relationship between the polarity of acetic acid and water,. Thus, as the solvent polarity decreased the amount of $\alpha$-helical content of the prolamin increased.

Generally, the spectra of the coacervated preparations (Figure 5D) were similar to those with water addition (Figure 5B). Almost all the different prolamin preparations had lower $\alpha$-helix conformation peaks than the $33 \%$ acetic acid treated preparations. Exceptions were the high $\alpha$-zein and high $\alpha$ kafirin minus $\gamma$ which both had higher levels of $\beta$-sheet conformation than when prepared with water. It is suggested that when the prolamin preparations were dissolved in glacial acetic acid, the proportion of $\alpha$-helical conformation present would be increased as shown by Elhassan et al. (2018) and then reduced when water was added during the coacervation process. This is similar to the effect found when total zein films were cast from glacial acetic acid and then made into visco-elastic 
masses with water (King et al., 2016). The proportion of $\beta$-sheet was slightly reduced when the protein was dissolved in glacial acetic acid and cast into a film and slightly increased again when the residual glacial acetic acid was removed.

Differential scanning calorimetry (DSC) was used to determine the $T_{\mathrm{g}}$ of the different prolamin preparations when dry (Figure 1S). Tg may be considered an indicator of polymer stability (Tang, Chen, Li, \& Yang, 2006), thus the higher the $T_{g}$, the more stable the protein is. Generally, the kafirin preparations were more thermally stable than the zein preparations. Commercial zein, which most readily formed visco-elastic masses (Figure 2), was the least stable, with a wide first transition starting from about $90^{\circ} \mathrm{C}$ up to $190^{\circ} \mathrm{C}$. Relating the effects of the secondary structure of the prolamins to changes in $T_{g}$ is highly complex because a range of factors are involved, especially protein-linking (Bengoechea, Arrachid, Guerrero, Hill, \& Mitchell, 2007). With prolamins, disulphide bonding can cause an increase in $\mathrm{T}_{\mathrm{g}}$, as observed by Sartor and Johari (1996) working with dry wheat gluten. Commercial zein as it is predominantly $\alpha$-zein has very low levels of cysteine and hence would exhibit low disulphide bonding and be the least stable, and kafirins with their relatively high levels of cysteine (Belton et al., 2006) should be the most stable, as found.

\subsection{Role of the various prolamin sub-classes in zein and kafirin visco-elastic mass properties}

It is evident that the process of solubilizing the prolamin preparations in glacial acetic acid followed by coacervation with water is required to obtain functionality of kafirin and zein, when all the subclasses are present. A high proportion of $\alpha$-sub-class prolamin appears to improve the functionality of both kafirin and zein. The increase in the proportion of the $\alpha$-subclass occurs with a concurrent decrease in the $\beta$ - and $\gamma$-prolamin sub-classes. However, removal of the $\gamma$-subclass of kafirin does not result in a significant improvement in functionality in terms of visco-elastic mass formation for either kafirin or zein. In fact, it appears that the $\gamma$-subclass is necessary for the retention of viscoelastic mass softness for both kafirin and zein, and is required for the retention of elastic recovery for coacervated kafirin visco-elastic masses on storage. For zein, regardless of the presence or 
absence of the $\gamma$-subclass, the coacervated visco-elastic masses had a large viscous component. Non-functional zeins have been characterised by a high $\beta+\gamma$-zein content (Schober et al. (2011). If visco-elastic masses can be formed in the presence of $\gamma$-kafirin or $\gamma$-zein, then it is suggested that the presence or absence of the $\beta$-sub-class, with its ability to form large polymers, may have more influence on the ability of kafirin or zeins visco-elastic masses to form, than does the presence or absence of the $\gamma$-sub-class. The $\beta$-kafirins (chain extenders) are thought to act as a bridge linking together $\gamma$ - and $\alpha 1$ - into larger polymers, whereas $\psi$-and $\alpha 1$-kafirin bind to $\alpha 2$-kafirin (chain terminator) through competitive linkage of disulphide- bonds to form small polymers (El Nour et al., 1998). Since there is evidence of a small amount of $\gamma$-zein in the commercial zein preparation it would appear that the formation of some small polymers is not detrimental to visco-elastic mass formation. However, the presence of $\beta$-zein or $\beta$-kafirin, with its capacity to form large polymers may prevent visco-elastic mass formation. This concept is supported by the fact that the kafirin minus $\gamma$-kafirin, containing $\beta$-prolamin was incapable of forming a visco-elastic mass with acetic acid above the protein's $\mathrm{T}_{\mathrm{g}}$. Elhassan et al. (2018) working with sorghum lines with $\beta$-kafirin expression suppressed found that the appearance of coacervated kafirin visco-elastic masses was improved when compared with kafirin extracted from normal sorghum lines containing all the prolamin subclasses but that the stress relaxation was not different. The influence of the $\beta$-sub-class on viscoelastic mass formation should be further investigated.

\section{Conclusions}

This study has shown that coacervation from glacial acetic acid allows the formation of visco-elastic masses from various different zein and kafirin preparations regardless of their sub-class composition, whereas other methods do not. This is presumably because dissolving the prolamins in glacial acetic acid enables protonation and complete solvation. Once formed, the kafirin and zein visco-elastic masses have different functional properties. Zein exhibits predominantly viscous flow properties on 
storage, whereas, kafirin is more elastic than zein. Gamma-kafirin is required to retain this elasticity when then the kafirin mass is stored.

\section{Acknowledgements}

Alan Hall of the University of Pretoria Laboratory for Microscopy and Microanalysis for assistance with the microscopy.

\section{References}

AACC, 2000. Approved Methods of the American Association of Cereal Chemists, 10th ed. AACC, St Paul, MN, USA.

Adebowale, A.A., Emmambux, M.N., Beukes, M.,\& Taylor, J.R.N. (2011). Fractionation and characterization of teff proteins. Journal of Cereal Science, 54, 360-366.

Anyango, J.O., Taylor, J.R.N., \& Taylor, J. (2013).Role of $\gamma$ kafirin in the formation and organization of kafirin microstructures. Journal of Agricultural and Food Chemistry, 61, 10757-10765.

Bean, S. R., loerger, B. P., Park, S.H., \& Singh, H. (2006). Interaction between sorghum protein extraction and precipitation conditions on yield, purity and composition of purified protein fractions. Cereal Chemistry, 83, 99-107.

Belton, P.S., Delgadillo, I., Halford, N.G., \& Shewry, P.R. (2006). Kafirin structure and functionality. Journal of Cereal Science, 44, 272-286.

Bengoechea, C., Arrachid, A., Guerrero, A., Hill, S.E., \& Mitchell J.R. (2007). Relationship between the glass transition temperature and the melt flow behaviour for gluten, casein and soya. Journal of Cereal Science, 45, 275-284.

Byaruhanga, Y.B., Erasmus, C., \& Taylor, J.R.N. (2005). Effect of microwave heating of kafirin on the functional properties of kafirin films. Cereal Chemistry, 82, 565-573.

Cremer, J.E., Bean, S.R., Tilley, M.M., loerger, B.P., Ohm, J.B., Kaufman, R.C., Wilson, J.D., Innes, D.J., Gilding, E.K., \& Godwin, I.D. (2014). Grain sorghum proteomics: integrated approach toward 
characterization of endosperm storage proteins in kafirin allelic variants. Journal of Agricultural and Food Chemistry, 62, 9819-9831.

Da Silva, L.S., \& Taylor, J.R.N. (2004). Sorghum bran as a potential source of kafirin. Cereal Chemistry, $81,322-327$.

Da Silva, L.S., Taylor, J., \& Taylor, J.R.N. (2011). Transgenic sorghum with altered kafirin synthesis: kafirin solubility, polymerization and protein digestion. Journal of Agricultural and Food Chemistry, $59,9265-9270$.

Duodu, K.G., Tang, H., Grant, A., Wellner, N., Belton, P.S., \& Taylor, J.R.N. (2001). FTIR and solid state ${ }^{13} \mathrm{C}$ NMR spectroscopy of proteins of wet cooked and popped sorghum and maize. Journal of Cereal Science, 33, 261-269.

Duodu, K.G., Nunes, A., Delgadillo, I., Parker, M.L., Mills, E.N.C., Belton, P.S., \& Taylor, J.R.N. (2002). Effect of grain structure and cooking on sorghum and maize protein in vitro digestibility. Journal of Cereal Science, 35, 161-174.

Duodu, K.G., Taylor, J.R.N., Belton, P.S., \& Hamaker, B.R. (2003). Factors affecting sorghum protein digestibility. Mini review. Journal of Cereal Science, 38, 117-131.

El Nour, N.A., Peruffo, A.D.B., \& Curioni, A. (1998). Characterisation of sorghum kafirins in relations to their cross-linking behaviour. Journal of Cereal Science, 28, 197-207.

Elhassan, M.S.M., Oguntoyinbo, S.I., Taylor J., \& Taylor, J.R.N. (2018). Formation and properties of viscoelastic masses made from kafirin by a process of simple coacervation from solution in glacial acetic acid using water. Food Chemistry, 239, 333-342.

Emmambux, M.N., \& Taylor, J.R.N. (2003). Sorghum kafirin interaction with various phenolic compounds. Journal of the Science of Food and Agriculture, 83, 402-407.

Emmambux, M.N., \& Taylor, J.R.N. (2009). Properties of heat-treated sorghum and maize meals and their prolamin proteins. Journal of Agricultural and Food Chemistry, 57, 1045-1050. 
Erickson, D. P., Campanella, O. H., \& Hamaker, B.R. (2012). Functionalizing maize zein in viscoelastic dough systems through fibrous, $\beta$-sheet-rich protein networks: An alternative, physicochemical approach to gluten-free breadmaking. Trends in Food Science and Technology, 24, 74-81.

Evans, D. J., Schüssler, L., \& Taylor, J. R. N. (1987). Isolation of reduced-soluble protein from sorghum starchy endosperm. Journal of Cereal Science, 5, 61-65.

King, B. L., Taylor, J., \& Taylor, J. R. N. (2016). Formation of a viscoelastic dough from isolated total zein ( $\alpha$-, $\beta$ - and $\gamma$-zein) using a glacial acetic acid treatment. Journal of Cereal Science, $71,250-257$. Kong, J. \& Yu, S. (2007). Fourier transform infared spectroscopic analysis of protein secondary structures. Acta Biochimica et Biophysica Sinica, 39, 549-559. Lawton, J. W. (1992). Viscoelasticity of zein-starch doughs. Cereal Chemistry, 69, 351-355. Lawton, J. W. \& Wilson, C.M. (2003). Proteins of the kernel. In P. J. White \& L.A. Johnson (Eds.)Corn Chemistry and Technology (pp .313-354) St. Paul, MN :AACC Inc..

Li, Y., Xia, Q., Zhang, B., Wang, Q., \& Huang, Q. (2012). Understanding the dissolution of $\alpha$-zein in aqueous ethanol and acetic acid solutions. Journal of Physical Chemistry116, 12057-1265.

Mejia, C. D., Mauer, L. J., \& Hamaker, B. R. (2007). Similarities and differences in secondary structure of viscoelastic polymers of maize $\alpha$-zein and wheat gluten proteins. Journal of Cereal Science, 45 , 353-359.

Oom, A., Pettersson, A., Taylor, J.R.N., \& Stading, M. (2008). Rheological properties of kafirin and zein prolamins. Journal of Cereal Science, 47, 109-116.

Sartor, G., \& Johari, G.P. (1996). Polymerization of a vegetable protein, wheat gluten, and the glassoftening transition of its dry and reacted state. Journal of Physical Chemistry, 100, 19692-19701. Schober, T. J., Bean, S. R., Tilley, M., Smith, B. M., \& loerger, B. P. (2011). Impact of different isolation procedures on the functionality of zein and kafirin. Journal of Cereal Science, 54, 241-249.

Schober, T. J., Moreau, R. A., Bean, S. R., \& Boyle, D .L. (2010). Removal of surface lipids improves the functionality of commercial zein in viscoelastic zein-starch doughfor gluten-free bread making. Journal of Cereal Science, 52, 417-425. 
Singh, H., Rockall, A., Martin, C. R., Chung, O. K., \& Lookhart, G. L. (2006). The analysis of stress relaxation data of some viscoelastic foods using a texture analyzer. Journal of Textural Studies, 37, 383-392.

Smith, B.M., Bean, S.R., Selling, G., Sessa, D., \& Aramouni, F.M. (2014). Role of non-covalent interactions in the production of visco-elastic material from zein. Food Chemistry, 147, 230-238.

Sly, A. C., Taylor, J., \& Taylor, J.R.N. (2014). Improvement of zein dough characteristics using dilute organic acids. Journal of Cereal Science, 60, 157-163.

Tang, G.H., Chen, Z.,Li, L., \& Yang X.Q. (2006). Effects of transglutaminase treatment on the thermal properties of soy protein isolates. Food Research International, 39, 704-711.

Taylor, J., Bean, S.R., loerger, B.P., \& Taylor, J.R.N. (2007). Preferential binding of sorghum tannins with gamma-kafirin and the influence of tannin binding on kafirin digestibility and biodegradation. Journal of Cereal Science, 46, 22-31.

Taylor, J., Taylor, J.R.N., Belton, P.S., \& Minnaar, A. (2009). Kafirin microparticle encapsulation of catechin and sorghum condensed tannins. Journal of Agricultural and Food Chemistry, 57, 75237528.

Taylor, J, Taylor, J.R.N., Dutton, M.F., \& De Kock S. (2005). Identification of kafirin film casting solvents. Food Chemistry, 90, 401-408.

Thermal Analysis UserCom 11. Interpreting DSC curves. Part 1: Dynamic measurements. Information for users of Mettler Toledo thermal analysis system. 1/2000. (http://uk.mt.com/dam/nonindexed/po/ana/ta-usercom/51710020_UserCom11_TA_e.pdf) (Accessed June 2017). Wang, Y., Rakotonirainy, A.M., \& Padua, G.W. (2003). Thermal behaviour of zein-based biodegradable films. Starch/Stärke, 55, 25-29.

Xiao, J., Li, Y., Li, J., Gonzalez, A.P., Xia, Q.,\&Huang, Q. (2014). Structure, morphology, and assembly behaviour of kafirin. Journal of Agricultural and Food Chemistry, 63, 216-224. 


\section{Appendix A. Supporting information description}

Table 1S: Effects of prolamin preparations and of water and acetic acid treatments on visco-elastic mass formation

\begin{tabular}{|c|c|c|}
\hline Prolamin preparations & Treatments & Visco-elastic mass formation ability \\
\hline \multirow[t]{4}{*}{ Kafirin } & Water & Could not form visco-elastic mass \\
\hline & 5.4\% Acetic acid & Could not form visco-elastic mass \\
\hline & $33 \%$ Acetic acid & $\begin{array}{l}\text { No visco-elastic mass formation but more cohesive } \\
\text { than with water, forming larger aggregates. Few } \\
\text { very fine fibrils observed by stereo microscopy }\end{array}$ \\
\hline & $\begin{array}{l}\text { Coacervated with } \\
\text { water from solution in } \\
\text { glacial acetic acid }\end{array}$ & $\begin{array}{l}\text { Formed large aggregates, which had some elastic } \\
\text { properties as they slowly bounced back when } \\
\text { pressed even when at ambient temperature. Few } \\
\text { very fine fibrils observed by stereo microscopy }\end{array}$ \\
\hline \multirow[t]{4}{*}{ High $\alpha$-kafirin } & Water & Could not form visco-elastic mass \\
\hline & $5.4 \%$ Acetic acid & Could not form visco-elastic mass \\
\hline & $33 \%$ Acetic acid & $\begin{array}{l}\text { No visco-elastic mass formation but more cohesive } \\
\text { than with water, formed larger aggregates which } \\
\text { had some elastic properties even when cooled } \\
\text { below ambient temperature. Few very fine fibrils } \\
\text { observed by stereo microscopy }\end{array}$ \\
\hline & $\begin{array}{l}\text { Coacervated with } \\
\text { water from solution in } \\
\text { glacial acetic acid }\end{array}$ & $\begin{array}{l}\text { Formed a visco-elastic mass with some elastic } \\
\text { properties even when cooled below ambient } \\
\text { temperature. Showed fibril/ribbon formation by } \\
\text { stereo microscopy. }\end{array}$ \\
\hline \multirow[t]{4}{*}{ Kafirin minus- $\gamma$} & Water & Could not form visco-elastic mass \\
\hline & 5.4\% Acetic acid & Could not form visco-elastic mass \\
\hline & $33 \%$ Acetic acid & $\begin{array}{l}\text { No visco-elastic mass formation but more cohesive } \\
\text { than with water or } 5.4 \% \text { acetic acid }\end{array}$ \\
\hline & $\begin{array}{l}\text { Coacervated with } \\
\text { water from solution in } \\
\text { glacial acetic acid }\end{array}$ & $\begin{array}{l}\text { Formed largish aggregates which had more elastic } \\
\text { properties than total kafirin under same conditions, } \\
\text { bounced back when pressed even when cooled } \\
\text { below ambient temperature. Few very fine fibrils } \\
\text { observed by stereo microscopy }\end{array}$ \\
\hline \multirow[t]{4}{*}{ High $\alpha$-kafirin minus $-\curlyvee$} & Water & Could not form visco-elastic mass \\
\hline & $5.4 \%$ Acetic acid & Could not form visco-elastic mass \\
\hline & $33 \%$ Acetic acid & $\begin{array}{l}\text { No visco-elastic mass formation but more cohesive } \\
\text { than with water. Few fibrils observed by stereo } \\
\text { microscopy }\end{array}$ \\
\hline & $\begin{array}{l}\text { Coacervated with } \\
\text { water from solution in } \\
\text { glacial acetic acid }\end{array}$ & $\begin{array}{l}\text { More cohesive than with acid, formed larger } \\
\text { aggregates, slightly elastic. Few very fine fibrils } \\
\text { observed by stereo microscopy }\end{array}$ \\
\hline \multirow[t]{2}{*}{ Zein } & Water & $\begin{array}{l}\text { Formed an aggregate which rapidly became brittle } \\
\text { on cooling }\end{array}$ \\
\hline & $5.4 \%$ Acetic acid & Formed an aggregate which rapidly became brittle \\
\hline
\end{tabular}




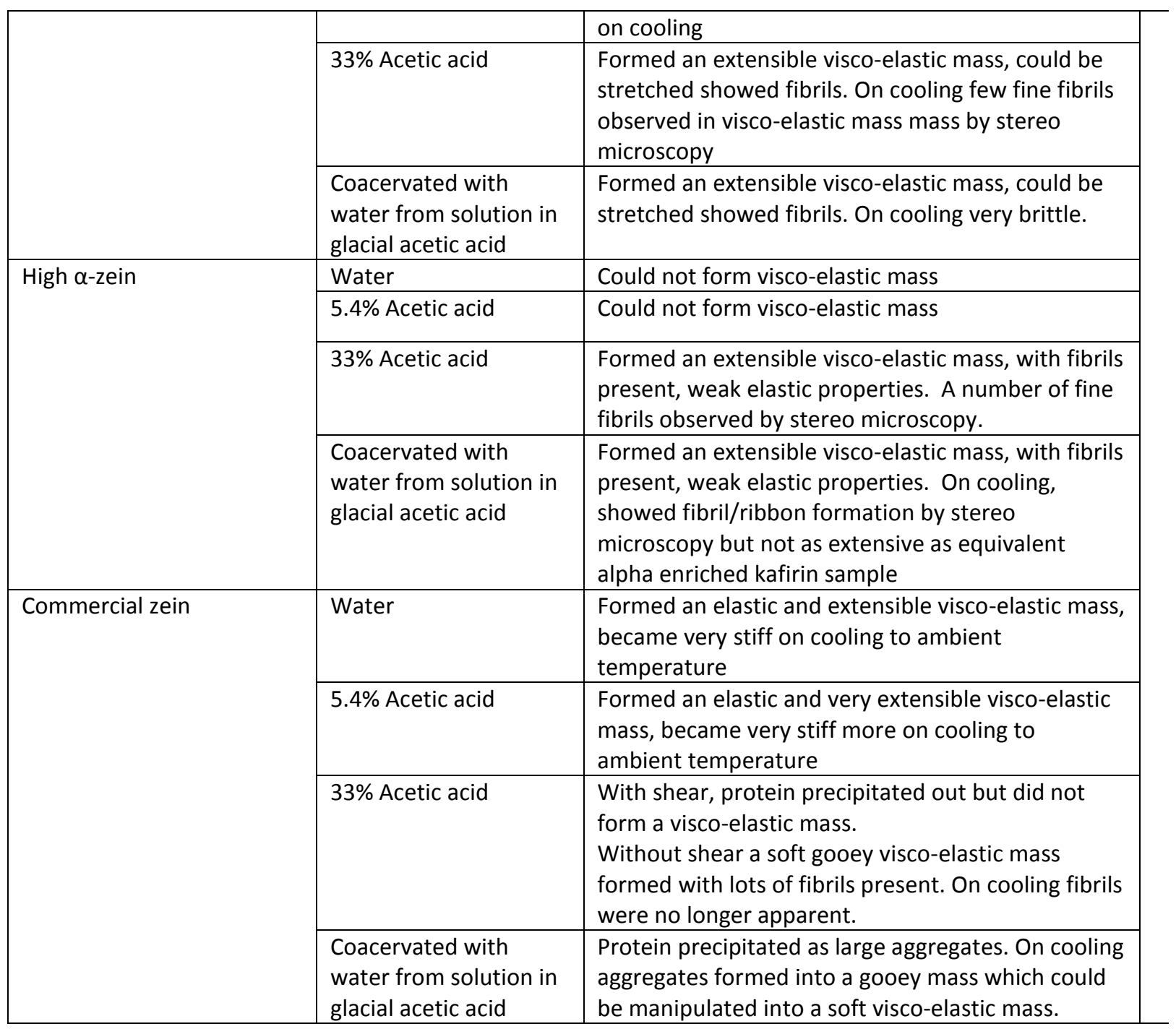




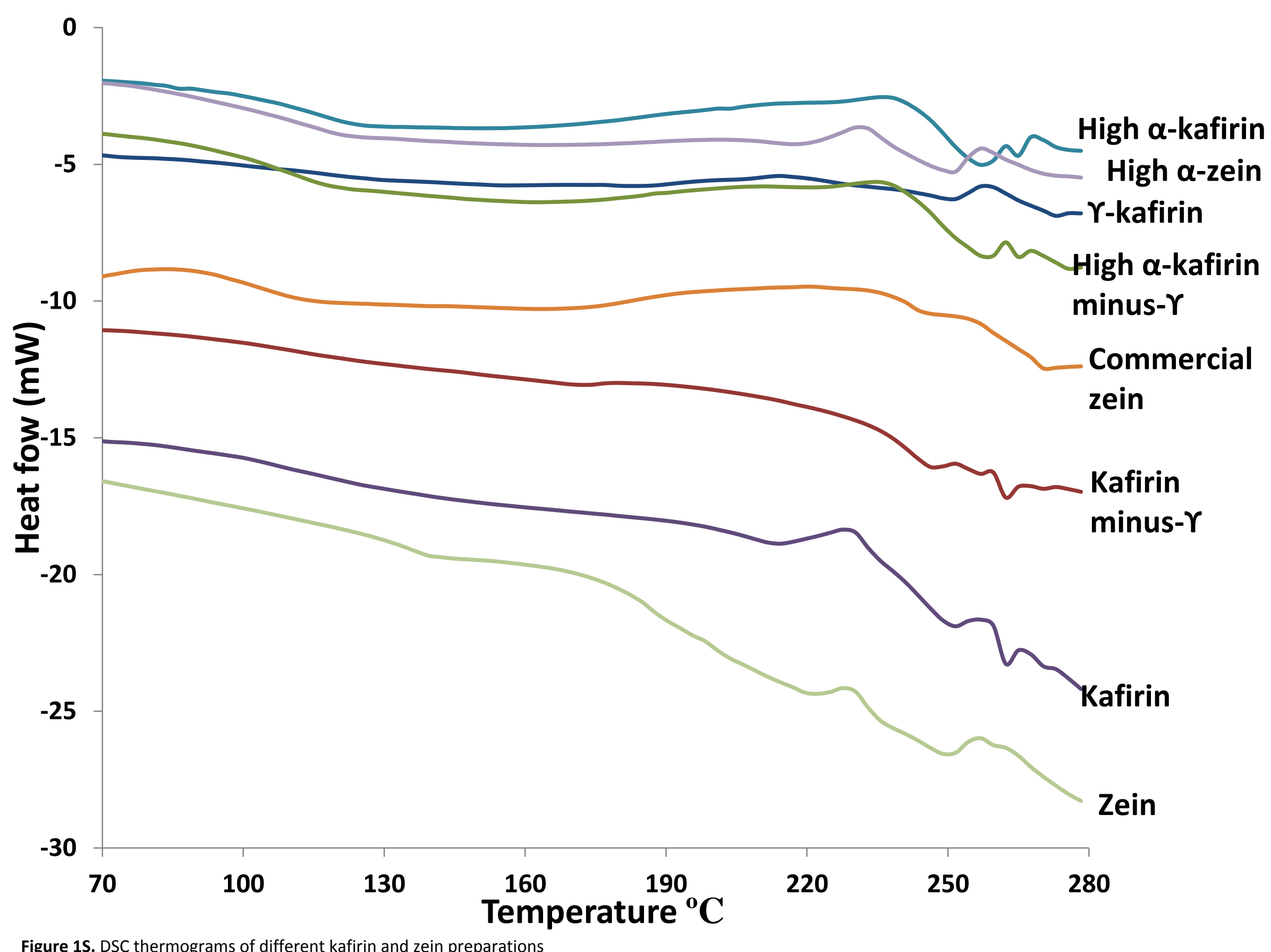

